\title{
DO MUNDO A SIGNIFICAR AO MUNDO SIGNIFICADO, O HUMOR VIRA NOTIÍCIA NO DISCURSO DA INFORMAÇÃO
}

Maria Aparecida Silva Furtado (FALE/UFMG)

\section{Introdução}

Segundo Mouillaud (2002:349), a morte é desnudada ao extremo na mídia. É apresentado todo um perfil do morto: nome de família, idade, etc. A morte, por sua vez, se torna, então, no jornal, um acontecimento, uma notícia. A análise que ora propomos desenvolver procura, a partir do corpus "a notícia da morte do humorista Cláudio Bessarman Viana, o Bussunda do grupo Casseta e Planeta, publicada no Jornal Estado de Minas, dia 18 de junho de 2006", estudar a mídia impressa, ou melhor, o jornal impresso, mais precisamente, a notícia. Com base nos estudos de Charaudeau e Mouillaud, temos o objetivo de refletir sobre o discurso de informação e, dentro desse, sobre uma notícia. Tal reflexão se dá por meio de uma análise das estratégias discursivas deste produto midiático em questão para a compreensão do discurso da informação.

Conforme bem expõe Charaudeau (2006:17), tentar analisar o discurso de informação por meio das mídias não é uma tarefa fácil, pois o mundo das mídias tem a pretensão de se definir contra o poder e contra a manipulação, apesar de este, sem querer, se prestar a uma manipulação das consciências e manipular até mesmo a si mesmo. Essa dupla face do discurso de informação pode ser associada como aquilo que chamamos de credibilidade e captação.

Antes de prosseguirmos, convém que definamos o que estamos chamando por informação e o que estamos entendendo por notícia. Informação é, para nós, aquilo que pode ser transmitida por um sinal ou conjunto de sinais que circulam na sociedade como um objeto de conhecimento ou como um objeto de memória armazenado no indivíduo. Gerir uma informação não é algo tão simples, pois se apresenta com um importante problema: sabedoria para unir uma informação nova 
com uma informação velha. Assim, a interação entre os interlocutores só existe porque há uma constante realimentação de informações circulando na sociedade.

De acordo com Charaudeau (2006:132), "notícia é um conjunto de informações que se relaciona a um mesmo espaço temático, tendo um caráter de novidade, proveniente de uma determinada fonte e podendo ser diversamente tratado". É a fonte, pois, a origem do acontecimento. Este, por sua vez, é convertido em informação e, sob forma discursiva, é submetida a descrições, a narrativas, e a análise dos fatos, dentro de uma cadeia temporal que tenta aproximar o instante do surgimento do acontecimento com o instante da produção midiática, gerando, assim, a relação do instante da saída do produto midiático e com o do consumo da notícia, que promoverá a interação entre os interlocutores.

No caso do nosso jornalismo brasileiro, a interação entre os interlocutores se passa por uma via do "desvelamento" da informação, no sentido de o jornal levar um saber ao destinatário. "Se numa primeira aproximação, informar é transmitir um saber a quem não o possui, pode-se dizer que a informação é tanto mais forte quanto maior é o grau de ignorância, por parte do alvo, a respeito do saber que lhe é transmitido" (Charaudeau, 2006:17). Isto põe uma contradição sobre a informação midiática que, se por um lado escolhe atingir um grande número de receptores, precisa basear-se numa hipótese fraca sobre um baixo teor de saber do alvo e, por outro lado, se deseja fornecer uma informação com alto teor de saber, necessita formular uma hipótese forte sobre o alto saber do alvo. É, portanto, neste jogo que as mídias tornam-se automanipuladas para despertar o interesse e tocar a afetividade do destinatário da informação.

O leitor, destinatário da informação, por sua vez, atua na passagem da virtualidade do jornal para a significação da existência dos acontecimentos informados. Assim como Mouillaud (2002:174), não estamos nos referindo ao leitor empírico "dotado de determinantes sociais, culturais, psicológicos etc., mas daquele que chamamos de o leitor 'visado' (...), virtual". 
Refletindo sobre o jornal impresso que é dispositivo do nosso objeto de estudo aqui selecionado, podemos dizer que, para cada gênero textual divulgado, há sempre a predominância de certa intenção, podendo os textos serem inteiramente argumentativos, inteiramente informativos ou serem argumentativos, informativos e explicativos ao mesmo tempo. Delimitando nossa reflexão apenas aos textos informativos, no nosso caso - a notícia, podemos dizer que eles revelam explicitamente ou implicitamente "a finalidade intencional da situação de comunicação, (aqui, de 'fazer saber'), a identidade dos parceiros da troca (aqui, 'daquele que dá a informação') e a natureza do propósito (aqui, do 'saber de conhecimento'e do saber de crença')" (CHARAUDEAU, 2004: 279).

É, portanto, a partir destas questões postas que analisaremos o corpus apresentado na próxima seção.

\section{2. $\mathrm{O}$ corpus}

\section{LUTO NO HUMOR ${ }^{1}$}

(Cláudio Besserman Vianna, do 'Casseta \& Planeta', morreu na manhã de ontem aos 43 anos, depois de sofrer um infarto fulminante na Alemanha. Velório será na sede do Flamengo)

CORPO DE BUSSUNDA CHEGA HOJE PARA ENTERRO NO RIO

Munique, Alemanha e Rio de Janeiro - Morreu ontem às $8 \mathrm{~h} 30 \mathrm{em}$ Munique, Alemanha (3h30 no horário de Brasília), depois de sofrer uma parada cardíaca, o comediante Cláudio Bersserman Vianna, o Bussunda, que integrava o elenco do programa Casseta \& Planeta, Urgente da TV Globo. Bussunda morreu no quarto do hotel onde estava hospedado, em Parsdorf, cidade próxima a Munique, no momento em que recebia atendimento de paramédicos que também pernoitavam no local. O corpo foi liberado pelas autoridades alemãs e embarcado em um vôo da Varig com previsão de chegada ao Brasil no início da manhã de hoje. O velório, que começa às $10 \mathrm{~h}$, será no Ginásio da sede Flamengo, no Rio. O humorista era flamenguista.O clube decretou luto de três dias.

\footnotetext{
${ }^{1}$ Estado de Minas. Belo Horizonte, Domingo, 18 de junho de 2006, Caderno Nacional, p. 12.
} 
Carioca, o comediante completaria 44 anos no dia 25. Era casado com o a jornalista Angélica Nascimento e tinha uma filha, Júlia, de 13 anos. De acordo com outros três integrantes do elenco do Casseta \& Planeta - Cláudio Manuel, Hélio De la Peña e Beto Silva, que também estavam na Alemanha para fazer um programa especial sobre a Copa do Mundo, Bussunda teria começado a passar mal na sexta-feira, durante uma partida de fuetbol contra hóspedes norteamericanos, no campo do hotel. "Ele se sentiu cansado e pediu para ficar no gol. O jogo não demorou meia hora e a gente parou por causa dele", conta Cláudio Manuel, seu amigo desde a infância.

Bussunda sofria de asma, conta Manuel, mas mesmo assim acharam estranho ele ofegar para caminhar a distância curta do campo até o hotel, menos de 100 metros. "Ele nunca se queixava de nada. Antes de entrar no hotel, coloquei a mão no ombro dele e senti seu pescoço frio. Perguntei se a gente não deveria consultar um médico. Só quero dormir, ele disse".

Um pouco mais tarde, preocupados, os colegas ligaram para seu quarto, mas ele disse que estava bem e repetiu que queria dormir. Acordou cedo, por volta das $7 \mathrm{~h}$, e, na hora em que tomava café, sentiu-se mal. "Ele disse que não precisava do médico, mas aí obrigamos ele a se consultar", diz Manuel. Ele foi atendido pelos paramédicos, que não conseguiram salvá-lo.

O cardiologista Flávio Cure Palheiro, médico de Bussunda havia oitos anos, disse que o humorista não tinha problemas cardíacos. Bussunda fazia check-ups freqüentes e no último deles, em janeiro, não mostrou evidência de nenhuma doença. "Ele vinha emagrecendo com nutricionista, fazia exercícios regularmente. $\mathrm{O}$ único fator de risco para a doença coronária é a história genética e o colesterol alto", afirmou o médico. A mãe do humorista, Helena Besserman Viana, morreu de enfarte há quatro anos. O humorista tinha pressão alta, que foi controlada. "O que se tem de objetivo até agora é que ele teve morte súbita", disse Palheiro, que soube por telefone da morte de Bussunda e deu a notícia à família.

Homenagem - Tanto Manuel como De la Peña não sabiam dizer qual seria o futuro do Casseta \& Planeta. "Não sei como vai ser ir para a redação e não vê-lo", disse Manuel. Não temos condições de pensar nisso agora", acrescentou. "Acredito que vamos fazer um esforço para continuarmos trabalhando, mas temos de ver a reação de cada um do grupo", disse De la Peña. A única certeza é que um programa será exibido com os melhores momentos do humorista, homenagem àquele que era um dos líderes do grupo. 
Bussunda era tido por seus colegas como o exemplo de alguém de alto astral. "Acho até que sua alegria dificultou o diagnóstico do problema, pois ele nunca queria incomodar ninguém e não queria atrapalhar as gravações. Ele era um Buda criativo e pacificador", disse Manuel, que conhecia Busunda desde os 10 anos. "chegamos a morar juntos e trabalhávamos lado a lado há 26 anos".

Os colegas que permaneceram no Rio, Marcelo Madureira, Hubert e Maria Paula, seguiram pela manhã para a casa da família de Bussunda, no Leblon, para consolar a mulher e a filha dele. "Estamos apoiando a nós mesmos porque somos a família também. Trabalhamos juntos durante 30 anos. Ele era o irmão de todos nós. A dor é imensa", disse Madureira. Para Maria Paula, Bussunda era o xodó do grupo. "Não posso descrever a dor que estou sentindo. Estou a 14 anos no grupo e a primeira coisa que fazia era falar com ele, quando chegava para gravar", diz ela. "Não sei como vai ser o programa sem ele".

\section{Da teoria à prática}

Tendo apresentado o corpus, vamos à analise. Conforme podemos perceber, nessa notícia, muitas são as descrições do tempo para transformar o acontecimento (a morte) em notícia. De acordo com Mouillaud (2002:174), num jornal diário, temos duas situações relativas ao tempo: o tempo do leitor e o leitor do tempo. O autor nomeia como sendo o "tempo do leitor a conduta temporal induzida pelo jornal diário". Já a expressão leitor do tempo pode ser associada ao uso que o leitor faz do seu tempo para a leitura do jornal: "cada número (do jornal) cai fora do tempo, mas sua leitura segue o fluxo do dia" (Ibidem, 175). Como exemplo dessa situação temos no corpus: 1) "o velório, que começa às 10h". Esta marcação "10h" é uma referência temporal tanto para o leitor que lê esta notícia antes deste horário, quanto para o leitor que a lê no final do dia. Há, é claro, uma mudança de postura dos dois leitores frente à informação que ele obtém de primeira mão. No caso do leitor do primeiro horário, parece haver uma atitude de expectativa da chegada das $10 \mathrm{~h}$ e, no caso do leitor do segundo tempo, parece existir uma atitude de queixa de ele não ter sabido/sentido o "ao vivo" do acontecimento (chegada do morto). Entretanto, o que marca a relação do leitor com a informação é o fluxo temporal 
da notícia. Esta, apesar da expectativa ou da queixa, tem validade por todo o dia, levando o leitor a se sentir inserido no mesmo tempo de publicação da notícia até que um novo número do jornal, num novo seguinte dia venha ocupar um novo tempo. A mesma análise poderia ser aplicada a outras indicações do tempo apresentada no corpus: 2) "ontem às 8 h30 em Munique, Alemanha (3h30 no horário de Brasília)", 3) "chegada (do corpo) ao Brasil no início da manhã de hoje”.

E por que essa análise se aplicaria aos outros dois exemplos acima? Por que o número do jornal diário (o seu tempo de validade temporal) está conectado à leitura do leitor e esta o conecta ao mundo atual que tenta aproximar o instante da saída do produto midiático com o instante de consumo da notícia, num movimento alocutivo do discurso da informação, diferente, pois, da narrativa de histórias que situa o leitor num além, sem relação como instante do aqui hoje.

Segundo Charaudeau (1994:08), todo discurso (considerando, pois, as diversas formas contratuais e os inúmeros gêneros discursivos) é realizado no interior de uma situação de comunicação a qual é composta de certo número de regras fixas que sobredeterminam os parceiros do ato de comunicação e estabelecem um contrato de comunicação. O discurso da informação não foge à regra.

De acordo com Charaudeau, (2006:129), o contrato de comunicação midiática se constitui como um quadro de restrições no qual se desdobra a encenação do discurso de informática e impõe um modo de organização do discurso em um ordenamento temático.

No caso do corpus em questão, a temática que norteia a informação é a morte do humorista. Já o modo de organização desta informação, este é construído, basicamente, por meio duas formas: o modo descritivo e o modo narrativo. Exemplificando parcela do modo descritivo, citemos: 4) “(...) depois de sofrer uma parada cardíaca (...)” , 5) “(...) no momento em que recebia atendimento de paramédicos que também pernoitavam no local (...)", 6) "O humorista era flamenguista". Quanto ao modo narrativo, destacamos: 7) “(...) morreu no quarto 
do hotel onde estava hospedado, em Parsdorf, cidade próxima a Munique, no momento em que recebia atendimento de paramédicos que também pernoitavam no local". 8) "O corpo foi liberado pelas autoridades alemãs e embarcado em um vôo da Varig (...)". 9) "Carioca, o comediante completaria 44 anos no dia 25. Era casado com o a jornalista Angélica Nascimento e tinha uma filha, Júlia, de 13 anos". 10) "De acordo com outros três integrantes do elenco do Casseta \& Planeta - Cláudio Manuel, Hélio De la Peña e Beto Silva, que também estavam na Alemanha para fazer um programa especial sobre a Copa do Mundo, Bussunda teria começado a passar mal na sexta-feira, durante uma partida de futebol contra hóspedes norte-americanos, no campo do hotel".

Dentro do modo de organização desta notícia, cabe-nos verificar o como é descrita a descrição e como é contada a narrativa. Assim, a morte do humorista é informação na medida em que tal fato é descrito por atores e ações e é explicado por testemunhas que dão credibilidade à informação noticiada. Como testemunha do acontecimento que virou notícia, a instância produtora apresenta, dentre outros, os amigos do morto, que ora exemplificamos: 11) "De acordo com outros três integrantes do elenco do Casseta \& Planeta - Cláudio Manuel, Hélio De la Peña e Beto Silva (...)".

Segundo Charaudeau, (1997), (apud Emediato 2005: 112), “a situação de comunicação midiática se encontra numa posição contraditória. Ela se liga, por um lado, à credibilidade do jornal e da própria informação e, por outro lado, à busca de captação do leitorado que se dá por meio do uso de suas próprias estratégias de sedução através de formas retóricas e interpelativas".

Essa posição contraditória em que se encontra o discurso da informação pode levar a mídia, no caso retratada aqui por meio da notícia em análise, a ser considerada séria por um lado, mas também ser considerada suspeita por outro. Uma das estratégias utilizadas para dar credibilidade à informação noticiada é o efeito de testemunho (Charaudeau, 2006) ${ }^{2}$, ou seja, a declaração emanada dos

\footnotetext{
${ }^{2}$ CHARAUDEAU, Patrick. Discurso das mídias.São Paulo: Contexto, 2006.
} 
locutores que descreveram o que viram ou ouviram a respeito da vida e morte do Bussunda: 12) "Ele se sentiu cansado e pediu para ficar no gol. O jogo não demorou meia hora e a gente parou por causa dele", conta Cláudio Manuel, seu amigo desde a infância". 13) "Bussunda sofria de asma, conta Manuel". 14) "Ele disse que não precisava do médico, mas aí obrigamos ele a se consultar", diz Manuel". 15) "Ele vinha emagrecendo com nutricionista, fazia exercícios regularmente. O único fator de risco para a doença coronária é a história genética e o colesterol alto”, afirmou o médico. 16)“O que se tem de objetivo até agora é que ele teve morte súbita, disse Palheiro, que soube por telefone da morte de Bussunda e deu a notícia à família". 17) "Não sei como vai ser ir para a redação e não vê-lo", disse Manuel. Não temos condições de pensar nisso agora, acrescentou”. 18) "Acredito que vamos fazer um esforço para continuarmos trabalhando, mas temos de ver a reação de cada um do grupo", disse De la Peña”.19) “Estamos apoiando a nós mesmos porque somos a família também. Trabalhamos juntos durante 30 anos. Ele era o irmão de todos nós. A dor é imensa", disse Madureira". 20) "Não posso descrever a dor que estou sentindo. Estou a 14 anos no grupo e a primeira coisa que fazia era falar com ele, quando chegava para gravar, diz ela" (Maria Paula).

Conforme podemos verificar, é muito grande o uso dos comentários de testemunhas nesta notícia. A modalidade da enunciação, neste caso, exerce um importante papel, pois ajuda a construir as visadas do fazer saber e do fazer sentir e é expressa por meio dos verbos de modalidade: 21) "conta Cláudio Manuel, seu amigo desde a infância", 22) "diz Manuel", 23) "O cardiologista Flávio Cure Palheiro, médico de Bussunda havia oitos anos, disse que o humorista não tinha problemas cardíacos", 24) "afirmon o médico", 25) "disse Palheiro", 26) "disse Manuel” (...) “acrescentou”, 27) “disse De la Peña” 28) “disse Madureira” 29) “diz ela” (Maria Paula). Com estes testemunhos, a instância de produção cumpre as exigências de identificação (fontes e signatários) obtendo maior credibildade (visada do fazer saber) e captação (visada do fazer sentir) para a informação apresentada. 
A credibilidade, por um lado, visa produção de efeitos de verdade da instância produtora, levando-a a apresentar tais estratégias que a faz ser levada a sério, mantendo-se numa posição de neutralidade a partir das suas escolhas de argumentos e palavras. A captação, por outro lado, atinge os universos das crenças e dos estados emocionais. A estratégia de captação, aqui, é apoiada no sentimento de perda que as testemunhas declaram sentir.

É, portanto, a partir desde construto enunciativo que a instância da produção mediática transforma a morte do humorista Cláudio Bessarman Viana, o Bussunda do grupo Casseta e Planeta, em notícia. A análise das estratégias discursivas deste produto midiático em questão serviu para refletirmos sobre o discurso da informação que se forma por meio do processo de transformação do mundo a significar em o mundo significado.

\section{Referências Bibliográficas}

CHARAUDEAU, Patrick. Discurso das mídias.São Paulo: Contexto, 2006.

CHARAUDEAU, Patrick. Dicionário de análise do discurso.São Paulo: Contexto, 2004.

EMEDIATO, Wander. O problema da informação midiática entre as ciências da comunicação $e$ a análise do discurso. In: MACHADO, I. L. et al. Movimentos de um percurso em Análise do discurso. Belo Horizonte: FALE/UFMG, 2005.

ESTADO DE MINAS. Belo Horizonte, Domingo, 18 de junho de 2006, Caderno Nacional, p. 12.

MOUILLAUD, M. PORTO, S. (orgs.) O jornal. Da forma ao sentido. Brasília: UNB, 2002. 